\title{
Chronic total occlusion of left anterior coronary artery in multivessel heart disease: between recommendations and reality
}

\author{
Jozica Šikić, Jasna Čerkez Habek* \\ University Hospital "Sveti Duh", Zagreb, Croatia
}

\begin{abstract}
A 55-year old patient was adimtted in hospital with symptoms of stable angina and positive treadmill test in inferolateral leads. Stress scintigraphy was performed and showed signs of ischaemia in posterolateral, anteroseptal and apical region. Coronarography showed chronic total occlusion (CTO) of mid-distal segment of RCA, proximal segment of $L A D$, and borderline stenosis in $A C x$. $\mathrm{PCl}$ was performed with successful recanalization of both CTOs and implantationes of DESs. A few months later he had less symptoms and normal treadmill test.
\end{abstract}

Studies reported that a successful CTO revascularization was associated with a 10-year survival advantage in comparison with failed CTO revascularization $(73.5 \%$ vs. $65.1 \%$, $\mathrm{p}=0.001)^{1}$. Patients with successful PCI CTO had a lower incidence of death or myocardial infarction (1.05\% vs. $7.23 \%$ at 12 months) $)^{2}$. Despite rapid advances in the technology and experience (retrograde and anterograde approach), the success rate remains about $60-80 \%$ in comparison with the success rates of more than $90 \%$ in non-CTO $\mathrm{PCls}^{3}$. Heavy calcification of CTO has been reported to be an independent predictor of failed $\mathrm{PCl}$ of $\mathrm{CTO}^{4}$. Cardiovascular magnetic resonance imaging may help in assessment of regional ventricular function, myocardial perfusion and viability. Presence of CTO in a non-infarct related artery is an independent predictor of mortality and is associated with a worse clinical outcome rather than the presence of multivessel disease ${ }^{6}$. Some studies showed that there is no statistical difference in cardiac mortality and morbidity at follow up between $C A B G$ and DES groups. However, the risk of subsequent revascularization was significantly lower among patients undergoing $C A B G$, and the rate of MACE was significantly higher in the DES group?

Obtaining a complete revascularization is crucial for decreasing cardiac events. We can do more CTOs and multivessel disease patients in our cath labs, but unfortunately the main limit is our cath lab budgets.

KEYWORDS: chronic total occlusion, coronary artery disease, revascularisation.

\footnotetext{
Received: $3^{\text {rd }}$ Mar 2013

*Address for correspondence: Klinička bolnica "Sveti Duh", Sveti Duh 64, HR-10000 Zagreb, Croatia.

Phone: +385-1-3712-111

E-mail: jasna.habek@gmail.com
}

\section{Literature}

1. Suero JA, Marso SP, Jones PG, Laster SB, Huber KC, Giorgi LV, et al. Procedural outcomes and long term survival among patients undergoing percutaneous coronary intervention of a chronic total occlusion in native coronary arteries: a 20 ysears expirience. J Am Coll Cardiol. 2011;38:409-14.

2. Olivari Z, Rubartelli P, Piscione F, et al. Immediate results and one-year clinical outcome after percutaneous coronary interventions in chronic total occlusions: data from a multicenter, prospective, observational study (TOAST-GISE). J Am Coll Cardiol. 2003;41:1672-8.

3. Patel VG, Brayton KM, Tamayo A, Mogabgab O, Michael TT, Lo N, et al. Angiographic success and procedural complications in patients undergoing percutaneous coronary chronic total occlusion interventions: a weighted meta-analysis of 18,061 patients from 65 studies. JACC Cardiovasc Interv. 2013;6:128-36.

4. Niccoli G, De Felice F, Belloni F, Fiorilli R, Consentio N, Fracassi F, et al. Late (3 years) follow-up of succesful versus unsuccesful revascularisation in chronic total coronary occlusion treated by drug eluting stent. Am J Cardiol. 2012;110:948-53.

5. Soona KH, Selvanaygamb JB, Coxa N, Kellya AM, Bella KW, Lima LY. Percutaneos revascularization of chronic total occlusion: review of the role of invasive and non invasive imaging modalities. Int J Cardiol. 2007;116:1-6.

6. DeFelice F, Fiorilli F, Parma A, Musto C, Nazzaro MS, Confessore P, et al. Effect of multivessel coronary artery disease with or without concomitant chronic total occlusion on 1-year survival in patients treated with rescue angioplasty. J Invas Cardiol. 2013;25:64-8.

7. Liu W, Chang Sheng MA, Kang J, Xin DU, Fang C. Comparison of drug eluting stent implantation with coronary artery bypass surgery in the treatment of patients with chronic total occlusion and multiple vessel disease. Chin Med J. 2011;124:1169-74. 